\title{
APTIDÃO CLIMÁTICA E ÉPOCA DE SEMEADURA DO GIRASSOL PARA A REGIÃO DE ITUVERAVA-SP
}

\author{
CRUPELATI, André Luís Fernandes ${ }^{1}$ \\ GARCIA, Anice ${ }^{2}$ \\ GARCIA, Lívia Cordaro Galdiano
}

\begin{abstract}
RESUMO: O presente trabalho foi realizado com o objetivo de analisar diferentes períodos de semeadura e cultivo de girassol para a região de Ituverava-SP, relacionados com os elementos agroclimáticos e suas influências. Os dados diários de elementos climatológicos foram coletados na estação agrometeorológica da Faculdade "Dr. Francisco Maeda" - FAFRAM, no período de 2001 a 2010. A precipitação foi obtida através de um Pluviômetro Ville de Paris e as temperaturas máximas e mínimas do ar com o uso de Termômetros de Máxima e Mínima, instalados dentro de um Abrigo Meteorológico. Com base nos critérios utilizados e nas exigências climáticas estudados da cultura do girassol, a região pode ser considerada uma região apta ao cultivo, baseados nos valores médios de temperatura e de precipitação, sendo novembro o melhor mês para o plantio.
\end{abstract}

Palavras-chave: Clima. Precipitação. Balanço hídrico. Helianthus annuus

\section{CLIMATE APTITUDE AND SOWING SEASON FOR SUNFLOWER IN THE REGION OF ITUVERAVA-SP}

SUMMARY: This study was conducted to analyze different periods of sowing and cultivation of sunflower seed for the region Ituverava-SP, related agro climatic elements and their influences. Daily data elements were collected climatological weather station at College "Dr. Francisco Maeda" - FAFRAM in the period 2001 to 2010. The precipitation was achieved by a Rain Gauge Ville de Paris and the maximum and minimum temperatures of the air with the use of Maximum and Minimum thermometers are installed inside a Weather Shelter. Based on the criteria used and studied in the climatic requirements of the sunflower crop, the region can be regarded as an area suitable for cultivation, based on average temperature and precipitation, and in November the best month for planting.

Keywords: Climate. Precipitation.Water balance. Helianthus annuus

\section{INTRODUÇÃO}

O girassol está entre as quatro maiores culturas oleaginosas produtoras de óleo vegetal comestível do mundo, ficando atrás da soja $\left(1^{\circ}\right)$, do algodão $\left(2^{\circ}\right)$, do amendoim $\left(3^{\circ}\right)$. Fonte energética renovável, como fonte de proteína humana e animal, possui um cultivo estimado de 20 milhões de hectares em todo o mundo. Rússia, Argentina e Estados Unidos, são os maiores produtores (CAVASIN Jr. 2001). A cultura do girassol apresenta inúmeras características para o seu crescimento no Brasil, devido a sua adaptabilidade nas várias regiões, resistência a veranicos, baixo custo de produção tornando excelente opção para plantio em época de safrinha. Apresenta ampla adaptabilidade às diferentes condições edafoclimáticas e seu rendimento é pouco influenciado pela latitude, pela altitude e pelo fotoperíodo (EMBRAPA, 2010a). Silva (1990) diz que o girassol é uma planta adaptada a regiões de climas variados, desde quentes até temperados sendo que é encontrada culturas em climas frios. Graças a essas

\footnotetext{
${ }^{1}$ Engenheiro Agrônomo- FE/FAFRAM

${ }^{2}$ Dra. em Agronomia (Ciência do solo); pós-graduação em Agrometeorologia. Docente na Unesp/Jaboticabal e na FE/ FAFRAM.

${ }^{3}$ Dra. em Agronomia (Produção Vegetal). Docente na FE/FAFRAM
} 
características, apresenta-se como uma opção nos sistemas de rotação e sucessão de culturas nas regiões produtoras de grãos (EMBRAPA, 2010a).

O cultivo dessa espécie está sujeito às variações edafoclimáticas, em especial a disponibilidade hídrica do solo, na ocasião da semeadura (BACKES et al., 2008). A EMBRAPA (2011a) recomenda o plantio no estado de São Paulo nos meses de fevereiro a março, utilizando cultivares de ciclo que variam de 90 a 130 dias, sendo que o florescimento ocorre, em média, 60 dias após a semeadura. Em Goiás, o período de semeadura vai do final de janeiro a fevereiro, no Paraná, de agosto a meados de outubro, no Rio Grande do Sul, de julho a agosto. Entretanto, sabe-se que ocorre interação entre genótipos e ambientes, havendo variação do comportamento de cultivares em função da região e época de plantio (PORTO et al., 2007).

O objetivo do presente trabalho foi verificar para a região de Ituverava-SP quais os períodos de semeadura e cultivo de girassol, levando-se em conta os elementos agroclimáticos.

\section{MATERIAL E MÉTODOS}

O trabalho foi desenvolvido com dados de precipitação e temperatura coletados na estação agrometeorológica da Faculdade "Dr. Francisco Maeda", localizada no município de Ituverava-SP, cujas coordenadas geográficas são: $20^{\circ} 20^{\prime} \mathrm{S} ; 47^{\circ} 46^{\prime} \mathrm{W}$ e altitude de 619 metros, com temperatura média anual de $22,8{ }^{\circ} \mathrm{C}$ e precipitação média anual de $1569 \mathrm{~mm}$. O clima da região, de acordo com a classificação de Köppen, é Aw, com verão úmido e inverno seco (CARRER; GARCIA, 2007).

O periodo de coleta de dados para análise das condições meteorológicas ocorridas foi de 2001 a 2010. Os dados de precipitação foram obtidos através da leitura de um pluviômetro Ville de Paris. A precipitação mensal foi constituída da somatória das precipitações diárias dentro dos meses analisados e reunidos em uma média para o período de 10 anos analisados.

Os dados de temperatura foram obtidos através de um termômetro de máxima (temperatura máxima) e um termômetro de mínima (temperatura mínima), e a temperatura media foi obtida pela media entre esses dois valores.

Esses dados foram utilizados na elaboração do balanço hídrico climatológico, empregando-se o método de Thornthwaite; Mather (1955).

Os elementos foram observados diariamente, e posteriormente anotados e arquivados em planilhas do Microsoft Excel no laboratório de agrometeorologia da Faculdade "Dr. Francisco Maeda" (FAFRAM) e para a confecção de gráficos e tabelas, utilizaram-se valores totais e média de precipitação, e médias para temperatura.

A temperatura durante o crescimento deve ser de 15 a $30{ }^{\circ} \mathrm{C}$ da florescência à colheita (PELEGRINI, 1985; EMBRAPA, 2010c). Temperaturas baixas aumentam o ciclo da cultura, atrasando a floração e a maturação. Quando ocorrem após o início da floração, podem afetar significativamente o rendimento. Temperaturas altas prejudicam o desenvolvimento da planta principalmente em condições de baixa disponibilidade hídrica. A faixa de temperatura de 8 a $34^{\circ} \mathrm{C}$ é tolerada pelo girassol sem redução significativa da produção, indicando adaptação a regiões com dias quentes e noites frias. A temperatura ótima para o seu desenvolvimento situa-se entre 27 a $28^{\circ} \mathrm{C}$. Temperaturas acima de $35^{\circ} \mathrm{C}$ reduzem o teor de óleo (EMBRAPA, 2010c). Segundo a Organização das Nações Unidas para a Agricultura e a Alimentação (FAO, 2011) as temperaturas médias diárias para um bom crescimento estão entre 18 e $25^{\circ}$ C. Silva (1990), entretanto, considera um limite um pouco mais amplo de temperaturas para a cultura, entre 13 a $30^{\circ} \mathrm{C}$, durante o ciclo, sendo que nas primeiras fases existe uma maior resistência às geadas que diminuem até a época do florescimento.

As necessidades hídricas do girassol ainda não estão perfeitamente definidas, existindo 
informações que indicam desde menos de $200 \mathrm{~mm}$ até mais de $900 \mathrm{~mm}$ por ciclo, sendo que 500 a 700 $\mathrm{mm}$ de água, bem distribuídos ao longo do ciclo, resultam em rendimentos potenciais (EMBRAPA, 2010c). Valores da necessidade de água da cultura do girassol variando de 600 a $1000 \mathrm{~mm}$, dependendo do clima e da duração do período de crescimento total, são preconizados pela FAO (2011), enquanto que dados técnicos indicam que 250 a $400 \mathrm{~mm}$ de chuva são suficientes para que a cultura se desenvolva. Para obter bons rendimentos, o girassol precisa de chuvas bem distribuídas até o momento do florescimento, entretanto, Ungaro (2000) considera que há necessidade de água suficiente para emergência uniforme, seguido de pelo menos $300 \mathrm{~mm}$ de chuva até o florescimento, bem distribuídos, e de menos $80 \mathrm{~mm}$ após o florescimento, na fase de enchimento de grãos, para que a planta não sofra deficiência hídrica.

Silva, (1990) observa que o girassol é uma planta que tem alto coeficiente de transpiração, mas não se percebe facilmente o murchamento. As chuvas são importantes nas fases de germinação, florescimento e enchimento dos grãos do capítulo, sendo necessário no mínimo $250 \mathrm{~mm}$ bem distribuídos, durante o ciclo.

$\mathrm{Na}$ fase de florescimento a ocorrência de chuvas excessivas afeta a fecundação, gerando a formação de aquênios vazios, com queda na produção. No estágio de pré-maturação, a baixa umidade relativa do ar é favorável ao desenvolvimento da planta, pois evita a disseminação de doenças. A água é crítica para a formação do óleo na época entre a formação das flores nos capítulos e o amadurecimento dos aquênios. A falta de água neste intervalo acarreta a diminuição no conteúdo do óleo dos aquênios (PELEGRINI, 1985).

Assim, da mesma forma que a água é importante no início da cultura, o excesso na colheita também deve ser evitado, pois prejudica a qualidade do óleo devido ao deterioramento dos capítulos (SILVA, 1990).

A partir de dados da literatura acima a respeito as exigências climáticas da cultura do girassol foi realizada uma análise das condições climatológicas nos períodos estudados da região para o desenvolvimento da cultura, segundo a tabela 1.

Tabela 1. Temperatura máxima (Tmax), temperatura mínima (tmin) temperatura média (TM) e precipitação (P) médias mensais para o período de 2001 a 2010. Ituverava, SP.

\begin{tabular}{lcccc}
\hline Mês & $\mathrm{Tmax}\left({ }^{\circ} \mathrm{C}\right)$ & $\mathrm{Tmin}\left({ }^{\circ} \mathrm{C}\right)$ & $\mathrm{TM}\left({ }^{\circ} \mathrm{C}\right)$ & $\mathrm{P}(\mathrm{mm})$ \\
\hline Janeiro & 26,60 & 20,60 & 23,60 & 314,1 \\
Fevereiro & 31,00 & 20,40 & 25,70 & 185 \\
Março & 30,60 & 19,40 & 25,00 & 140 \\
Abril & 30,70 & 17,20 & 23,95 & 59,9 \\
Maio & 26,10 & 12,90 & 19,50 & 47,6 \\
Junho & 27,20 & 12,70 & 19,95 & 15,4 \\
Julho & 27,60 & 12,40 & 20,00 & 5,8 \\
Agosto & 30,00 & 13,80 & 21,90 & 14,2 \\
Setembro & 31,60 & 16,60 & 24,10 & 42,9 \\
Outubro & 31,60 & 18,90 & 25,25 & 112,1 \\
Novembro & 30,40 & 19,20 & 24,80 & 233,4 \\
Dezembro & 29,40 & 20,20 & 24,80 & 270,5 \\
\hline Anual & 29.40 & 17.20 & 23.30 & 1440.9 \\
\hline
\end{tabular}

\section{RESULTADOS E DISCUSSÃo}

Pode-se observar na Tabela 1 que as maiores Tmax foram nos meses de setembro e outubro, onde 
atingiu $32{ }^{\circ} \mathrm{C}$ e as menores Tmin no mês julho ficando em torno de $12{ }^{\circ} \mathrm{C}$, sendo que nas médias a maior no mês de fevereiro, e a menor no mês de maio. A média anual foi de $23{ }^{\circ} \mathrm{C}$, sendo que a Tmax anual foi de $29{ }^{\circ} \mathrm{C}$ e a Tmin anual de $17{ }^{\circ} \mathrm{C}$. Essas temperaturas estão na faixa considerada pelos autores como adequadas para o plantio do girassol (EMBRAPA, (2010 c); CAVASIN Jr. (2001); SILVA, (1990); FAO, (2011); PELEGRINI (1985)).

A região de estudo possui inverno seco e verão chuvoso, com um total de chuvas, baseando-se nos dez anos desse estudo, no inverno de $35,4 \mathrm{~mm}$, na primavera de $388,4 \mathrm{~mm}$, no verão de $769,6 \mathrm{~mm}$ e no outono um total de $247,5 \mathrm{~mm}$, totalizando um total de $1440,9 \mathrm{~mm}$ anuais de precipitação.

Na Figura 2 são apresentadas as médias mensais dos valores de balanço hídrico climatológico para o período de 10 anos estudado.

Figura 2: Balanço hídrico climatológico (BHC) médias mensais para o período de 2001 a 2010. Ituverava, SP.

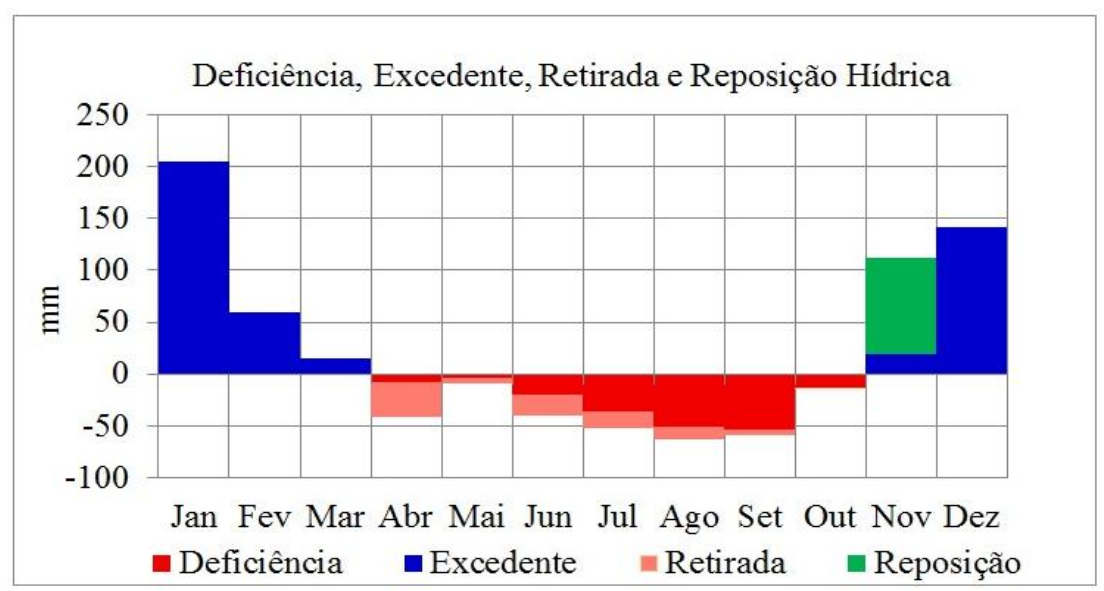

Pode-se observar que o período de deficiência hídrica nesses 10 anos estudados, foi de abril até outubro (183 mm), porém, nos meses de abril e maio essa deficiência não foi muito acentuada, visto o armazenamento de água no solo, e as precipitações ocorridas nesses meses. Em outubro, com o aumento do volume de precipitações (Tabela 1), a deficiência também foi menor, entrando em novembro com reposição de água no solo $(94 \mathrm{~mm})$ já atingindo a capacidade de armazenamento, uma vez que já houve excedente nesse mês (19 mm). Daí até março há um excedente hídrico de $441 \mathrm{~mm}$.

$\mathrm{Na}$ Tabela 2 são apresentadas as variações nas quantidades de precipitação total que ocorreriam do plantio a colheita do girassol considerando um ciclo médio de 120 dias, dependendo da época de semeadura.

Tabela 2. Precipitação em relação a época de semeadura e colheita do girassol considerando ciclo médio de 120 dias.

\begin{tabular}{lcccccr}
\hline Plantio/Colheita & Outubro & Novembro & Dezembro & Janeiro & Total \\
Precipitação (mm) & 112 & 233 & 270 & 314 & $\mathbf{9 2 9}$ \\
\hline & & & & & \\
\hline Plantio/Colheita & Novembr & Dezembro & Janeiro & Fevereiro & Total \\
Precipitação (mm) & o & 233 & 270 & 314 & 185 & $\mathbf{1 0 0 2}$ \\
\hline
\end{tabular}

(Continua) 
Tabela 2. Precipitação em relação a época de semeadura e colheita do girassol considerando ciclo médio de 120 dias.

(Conclusão)

\begin{tabular}{|c|c|c|c|c|c|}
\hline Plantio/Colheita & $\begin{array}{c}\text { Dezembr } \\
\text { o }\end{array}$ & Janeiro & Fevereiro & Março & Total \\
\hline Precipitação (mm) & 270 & 314 & 185 & 140 & 909 \\
\hline Plantio/Colheita & Janeiro & Fevereiro & Março & Abril & Total \\
\hline Precipitação (mm) & 314 & 185 & 140 & 60 & 699 \\
\hline Plantio/Colheita & Fevereiro & Março & Abril & Maio & Total \\
\hline Precipitação (mm) & 185 & 140 & 60 & 48 & 433 \\
\hline
\end{tabular}

Assim, como demonstrado na Tabela 2 o plantio do girassol sendo realizado em outubro, e considerando-se um ciclo de 120 dias, vai ter disponível um total de precipitação de $930 \mathrm{~mm}$ valor considerado como suficiente para o cultivo da cultura, mas apesar disso a colheita seria realizada no mês de janeiro o que, devido ao grande volume de precipitação poderia causar uma perda pela deterioração dos capítulos, devido a grande umidade e a impossibilidade de colheita. Já se o plantio for atrasado para novembro vai ter disponível um total de chuvas de $1003 \mathrm{~mm}$ volume considerado suficiente para a cultura se desenvolver e com isso possibilitaria a colheita em fevereiro, onde o volume de chuva diminui consideravelmente facilitando a colheita em dias secos. Se o plantio for atrasado para dezembro, vai haver um total de precipitação de $910 \mathrm{~mm}$, também considerado suficiente para o seu desenvolvimento e com isso a colheita seria realizada no mês de março, onde o volume de chuvas é menor, mas com uma impossibilidade de uma eventual safrinha com outro cultivo, visto isto, o ideal seria a utilização de cultivares de ciclo curto ou precoce que atingem a maturação fisiológica de 85 a 90 dias, totalizando um ciclo de 100 dias até a colheita, com isso seria possível se obter a colheita em fevereiro e possibilitando uma eventual safrinha.

O plantio sendo realizado em janeiro a cultura poderá enfrentar uma possível falta de chuva na fase de enchimento dos grãos em março, sendo o ideal utilizar cultivares precoce para esta época.

Se o plantio for realizado em fevereiro, ou seja, cultivo de safrinha, e considerando o mesmo ciclo de 120 dias, vai haver um total de 432,5 mm valor considerado insuficiente por alguns autores para o desenvolvimento da cultura. Pelegrini (1985), Ungaro (2000) e Silva (1990), consideram este valor suficiente (200-900 mm), a EMBRAPA (2010c) recomenda de 500 a $700 \mathrm{~mm}$, porém a FAO (2011) indica que o ideal seria de 600 a $1000 \mathrm{~mm}$. A utilização de um cultivar precoce, cujo florescimento pode ocorrer até duas semanas antes da demais (45 a 50 dias após a semeadura), permitiria que esta fase, que é a de maior necessidade hídrica da cultura, fosse suprida, para o plantio nesse período.

Para os demais meses (de março a setembro), não seria recomendado o plantio, visto que a cultura encontraria condições desfavoráveis ao cultivo, principalmente deficiência hídrica.

\section{CONCLUSÃO}

Pelos analise climática para o município de Ituverava, a cultura do girassol pode ser recomendada para a região, sendo que a época ideal para o plantio seria no mês de novembro, devido à ocorrência de precipitação e temperaturas adequadas para a cultura, o que possibilita a colheita para o mês de fevereiro, 
quando o volume de chuvas é menor. Isso ainda permitiria uma safrinha com a utilização de uma cultivar precoce.

Com relação à temperatura não há restrição térmica para o cultivo de girassol na região.

\section{REFERÊNCIAS}

BACKES, R.L. et al. Desempenho de cultivares de girassol em duas épocas de plantio de safrinha no planalto norte catarinense. Scientia Agricola, v.9, n.1, p.41-48, 2008. Disponível em:

http://ojs.c3sl.ufpr.br/ojs2/index.php/agraria/article/view/10131/8174. Acesso em: 30 de outubro de 2012.

CARRER, T.; GARCIA, A. Classificação climática para a cidade de Ituverava/SP. Nucleus, v.4, n.1, p. 11-10, 2007.

CAVASIN Jr, C. P. A Cultura do Girassol. Guaíba: Agropecuária, 2001. 69 p.

EMBRAPA - EMPRESA BRASILEIRA DE PESQUISA AGROPECUÁRIA. Embrapa Soja. Girassol. Disponível em: <http://www.cnpso.embrapa.br/index.php?op_page=54\&cod_pai=38>. Acesso em: 11 nov.2010a.

EMBRAPA - EMPRESA BRASILEIRA DE PESQUISA AGROPECUÁRIA. Embrapa Soja.

Tecnologias de Produção Girassol: Exigências Climáticas. Disponível em:

<http://www.cnpso.embrapa.br/producaogirassol/exigencias.htm>. Acesso em: 16 nov.2010b.

EMBRAPA - EMPRESA BRASILEIRA DE PESQUISA AGROPECUÁRIA. Embrapa Soja. Período de

Semeadura. Disponível em: 〈http://www.cnpso.embrapa.br/index.php?op_page=62\&cod_pai=154>.

Acesso em: 25 fev.2011.

EMBRAPA - EMPRESA BRASILEIRA DE PESQUISA AGROPECUÁRIA. Embrapa Soja.Tecnologias de Produção Girassol: Exigências Climáticas. Disponível em:

<http://www.cnpso.embrapa.br/producaogirassol/exigencias.htm>. Acesso em: 16 nov.2010c

FAO - Organização das Nações Unidas para a Agricultura e a Alimentação. Girassol: Exigências da água. Disponível em: <http://www.fao.org/landandwater/aglwcropwater/sunflower.stm>. Acesso em: 09 mar.2011.

LOPES, J. L. A vez do girassol. Disponível em: <http://www.embrapa.br/imprensa/artigos/2001/artigo> . Acesso em: 2004-12-07.2556958776/. Acesso em: 16 nov. 2010.

PELEGRINI, B. Girassol uma planta solar que das Américas conquistou o mundo. São Paulo: Ícone, 1985. $117 \mathrm{p}$.

PORTO, W.S.; CARVALHO, C.G.P.; PINTO, R.J.B. Adaptabilidade e estabilidade como critérios para seleção de genótipos de girassol. Pesquisa Agropecuária Brasileira, v. 42, p. 491-499, 2007.

SILVA, M. N. da. A Cultura do Girassol. Jaboticabal: Funep, 1990. 67p.

THORNTHWAITE, C.W.; MATHER, J.R. The water balance. New Jersey: Laboratory of Climatology, Drexel, Institute of Technology 1955, 140p.

UNGARO, M. R. G. Cultura do girassol. Campinas: Instituto Agronômico, 2000. 36p. Exigências da água. http://www.fao.org/landandwater/aglwcropwater/sunflower.stm.09 mar.2011. (Boletim técnico 188) 